\title{
Novas raças de Bremia lactucae, agente causador do míldio da alface, identificadas no estado de São Paulo
}

\author{
Jean de O Souza'; Tagli Dalpian²; Leila T Braz'; Margarete Camargo ${ }^{1}$ \\ ${ }^{1}$ UNESP-FCAV, Depto. Prod. Vegetal, Rod. Prof. Paulo Donato Castellane s/no , 14884-900 Jaboticabal-SP; jsoliveira1@hotmail.com; \\ leilatb@fcav.unesp.br; mcamargo@fcav.unesp.br; ${ }^{2}$ CATI-CA, Av. Gabriel Sanches 765, Centro, 15860-000 Ibirá-SP; tagli.dalpian@cati. \\ sp.gov
}

\section{RESUMO}

O objetivo deste trabalho foi relatar o surgimento de raças de Bremia lactucae, agente causal do míldio nas principais regiões produtoras de alface do estado de São Paulo. O estudo foi realizado no Laboratório de Melhoramento Genético de Hortaliças do Departamento de Produção Vegetal da UNESP, Campus de Jaboticabal. No período de 2006 e 2007, foram coletados 36 isolados de $B$. lactucae de diferentes regiões produtoras de alface no estado. Para identificação das raças foram utilizadas as cultivares diferenciadoras conforme o código "Sextet". Foram identificadas três novas raças, SPB1:02, SPB1:03 e SPB1:04 com os referidos comportamentos do fungo: $(63 / 31 / 19 / 00),(63 / 63 / 19 / 00)$ e $(63 / 63 / 03 / 00)$. Os genes Dm14, Dm-17, Dm-18, Dm-37 e Dm-38 conferem resistência a essas novas raças identificadas.

Palavras-chave: Lactuca sativa, genes Dm, resistência, melhoramento genético.

\begin{abstract}
New races of Bremia lactucae, causal agent of lettuce downy mildew, identified in São Paulo State, Brazil

The objective of this paper was to report new races of lettuce downy mildew causal agent Bremia lactucae in São Paulo State. The study was carried out in the laboratory of Crop Genetics in the Department of Crop Science at the college of Agricultural and Veterinary Sciences, Jaboticabal campus. A total of 36 isolates of $B$. lactucae was collected in different regions. The identification of races was based on compatibility reaction on the differential cultivars of the "Sextet". Three new races of B. lactucae, SPB1:02 (63/31/19/00), SPB1:03 (63/63/19/00) and SPB1:04 (63/63/03/00) were identified according to "Sextet" code. Genes Dm-14, Dm-17, Dm-18, Dm-37 and Dm-38 confer resistance to these new races identified.
\end{abstract}

Keywords: Lactuca sativa, Dm genes, resistance, genetic breeding.

(Recebido para publicação em 21 de outubro de 2010; aceito em 11 de julho de 2011)

(Received on October 21, 2010; accepted on July 11, 2011)

$\mathrm{O}_{\mathrm{s}}^{\mathrm{c}}$ cultivo da alface (Lactuca sativa L.) no estado de São Paulo concentra-se em torno da grande São Paulo, destacando-se Mogi das Cruzes como a maior área produtora (CATI, 2008). Em áreas menores, essa cultura distribui-se por todo o estado ao redor das principais cidades. A cultura no estado de São Paulo, em 2008, ocupou área de 5.800 ha, sendo produzidos 3.921 milhões de engradados de nove dúzias. O cinturão verde de São Paulo responde por grande parte desse volume comercializado, sendo a região de Mogi das Cruzes responsável por $45 \%$ da produção do estado (IEA, 2009).

Em um cenário econômico difícil para os produtores de alface, o míldio, doença causada pelo oomiceto do reino Stramenopila Bremia lactucae Regel, é um problema grave, pois aumenta os custos de produção no inverno, justamente quando os preços praticados são menores devido à maior oferta e ao menor consumo. O míldio é a mais importante doença nas condições de inverno, em regiões de temperatura amena, as quais coincidem com as condições observadas nas grandes regiões produtoras de alface do Estado de São Paulo (Pavan \& Kurozawa, 1997).

Os danos notórios às lavouras de alface no estado de São Paulo tiveram início a partir da década de 1990, porém ainda é desconhecida como ocorreu a entrada do patógeno no Brasil, ou se o mesmo já existia àquela época.

Van Ettekoven \& Van Der Arend (1999), visando uniformizar a identificação de raças de B. lactucae, padronizou por métodos de códigos denominados de "Sextet", em que cada raça possui um código, evitando que uma mesma raça receba denominações diferentes em distintas regiões do mundo. A necessidade dessa uniformização ocorreu devido ao surgimento de raças de $B$. lactucae em áreas fora da Europa e muita confusão foi criada quanto a sua identificação.

No período de 2003 a 2004, estudos pioneiros de identificação de raças, utilizando-se a mesma metodologia adotada também no presente trabalho, foram desenvolvidos nas regiões produ- toras de alface do estado de São Paulo, quando foi identificada a primeira raça de B. lactucae, denominada de SPB1:01 que predominava nesse estado (Braz et al., 2007).

Crute \& Johnson (1976) citam que o melhoramento para resistência da alface ao míldio foi iniciado por Jagger nos EUA(Califórnia) em 1926, e continuou na Europa e Israel.

A identificação de raças de $B$. lactucae é necessária para que programas de melhoramento com a cultura da alface sejam desenvolvidos visando o controle da doença, visto que esse patógeno apresenta pouca variabilidade genética devida seu modo mais fácil de reprodução ser assexuado, além de poucos trabalhos com identificação de raças de B. lactucae no Brasil. Porém é de extrema importância o seu monitoramento, pois uma vez identificada a raça, torna-se possível selecionar também os genes que conferem resistência à doença, possibilitando assim o desenvolvimento de linhagens de alface resistentes.

Diante do exposto, o objetivo do 
trabalho foi identificar a ocorrência de raças de míldio no período de 2006 a 2007 nas regiões produtoras de alface do estado de São Paulo, visando auxiliar programas de melhoramento genético da cultura.

\section{MATERIAL E MÉTODOS}

O estudo foi realizado no laboratório de melhoramento genético de hortaliças, do Departamento de Produção Vegetal da UNESP, Campus de Jaboticabal, SP.

Os isolados foram coletados em campos de produção de alface tipo crespa de vários produtores. As áreas amostradas representaram as áreas produtoras de alface do estado de São Paulo. Coletaram-se 20 folhas de alface com sintomas de míldio em áreas de produtores, sendo cada amostra assim considerada um isolado. Foram coletados 36 isolados de B. lactucae das regiões: cinturão verde (Mogi das Cruzes, Ibiúna e Piedade), Campinas, Botucatu, Ribeirão Preto e Marília nos anos de 2006 e 2007.

Em 2006, 20 isolados de B. lactucae foram coletados em campo de produção de alface tipo crespa no período de julho a agosto nas regiões: Ibiúna e Mogi das Cruzes (3 isolados por região), Araçatuba, Ribeirão Preto, Rio Claro, Bauru, São Carlos, Campinas e Araraquara (2 isolados por região).

Em 2007, 16 isolados de B. lactucae foram coletados nas regiões: Botucatu e Bauru (1 isolado por região), Piedade, Araraquara, Jaboticabal e Biritiba Mirim (2 isolados por região),Ibiúna e Ribeirão Preto (3 isolados por região).

Essas amostras foram embaladas em sacos plásticos, identificadas e acondicionadas em caixas térmicas e, em seguida, transportadas ao laboratório da UNESP-FCAV para a manutenção do inóculo.

A partir dos isolados coletados foram preparadas suspensões de esporângios e inoculados na concentração de (1 x $10^{5}$ esporângios $/ \mathrm{mL}$ ) por pulverização na cultivar suscetível Cobham Green (Dm-0/R?) em fase de plântulas e mantidas em estufa (BOD modelo EL212 eletrolab $_{\circledast}$ ) a $13^{\circ} \mathrm{C}$ e fotoperíodo de $12 \mathrm{~h}$.

Aos 15 dias após a inoculação observou-se esporulação dos isolados nas plântulas inoculadas, e daí foram mantidos no freezer $\mathrm{a}-20^{\circ} \mathrm{C}$ em tecidos foliares de plântulas. Essa ação foi repetida oito vezes consecutivamente para aumentar a quantidade e a viabilidade dos esporos que foram utilizados no teste de diferenciação de raças.

A inoculação dos isolados de $B$. lactucae nas diferenciadoras de alface foi feita de acordo com a técnica de Ilott et al. (1987). Utilizaram-se esporângios, lavados, de tecidos com presença de esporulação e agitados em água destilada. A concentração foi a mesma adotada para aumentar a quantidade de inóculo inicial, 1 x $10^{5}$ esporângios $/ \mathrm{mL}$, obtida através da contagem em câmara de Neubauer e pulverizados nas plântulas de cada cultivar diferenciadora de alface, aplicando-se $5 \mathrm{~mL}$ da suspensão para cada uma.

As sementes das cultivares diferenciadora de alface (Cobham Green, Odra, Lednicky, UC DM 2, Dandie, R4T57D, Valmaine, Sabine, LSE 57/15, UC DM 10, Capitan, Hilde II, Pennlake, UC DM 14, PIVT 1309, INRA DM 16, LS 102, Colorado, Ninja, Discovery e Argeles) foram semeadas separadamente. Utilizou-se caixas plásticas gerbox (11 x 11 x 3,5 cm) forradas com papel germitex umedecido e divididas em quatro partes iguais. Em cada uma das partes foram semeadas 30 sementes de cada cultivar diferenciadora. Após 12 dias da semeadura, obtiveram-se 30 plântulas de cada material, realizando-se as inoculações com os respectivos isolados. As plântulas de cada diferenciadora após as inoculações foram mantidas em estufa

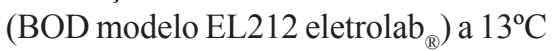
e fotoperíodo de $12 \mathrm{~h}$.

Após 15 dias da inoculação, foram feitas as avaliações, quando apareceram as esporulações na serie diferencial de alface. As avaliações foram realizadas nas plântulas, sendo estas avaliadas individualmente, verificando-se a presença ou não de lesões esporulantes, ou a reação necrótica com muitas ou poucas lesões esporulantes, seguindo a metodologia proposta por Van Ettekoven \& Van Der Arend (1999). Os critérios utilizados na avaliação dos testes de diferenciação de raças recebem o símbolo positivo: + quando $>80 \%$ das plântulas apresentaram-se com lesões esporulantes; símbolo positivo entre parêntese: $(+)$ quando $>80 \%$ das plântulas apresentaram pontos necróticos e com muitas lesões esporulantes; símbolo negativo: - $<5 \%$ das plântulas com lesões esporulantes; símbolo negativo entre parêntese: (-) plântulas com pontos necróticos e com poucas lesões esporulantes.

Todas as cultivares diferenciadoras são divididas em quatro grupos e são atribuídos valores de 1, 2, 4, 8, 16 e 32 a cada cultivar, segundo a metodologia de Van Ettekoven \& Van Der Arend (1999) como segue:

Grupo 1: Lednicky (1); UC DM 2 (2); Dandie (4); R4T57D (8); Valmaine (16); Sabine (32).

Grupo 2: LSE 57/15 (1); UC DM 10 (2); Capitan (4); Hilde II (8); Pennlake (16); UC DM 14 (32).

Grupo 3: PIVT 1309 (1); INRA DM 16 (2); LS 102 (4); Colorado (8); Ninja (16); Discovery (32).

Grupo 4: Argeles (1).

Após a inoculação, todos os genótipos da série diferencial caracterizados como suscetíveis aos determinados isolados tiveram seus valores somados dentro de cada grupo, e o resultado de cada grupo representado e separado por uma barra, da seguinte forma: 63/63/51/00. No referido exemplo, todas as cultivares do grupo 1 e 2 são suscetíveis $(1+2+$ $4+8+16+32=63$ ). Nas cultivares do grupo 3, somente a LS 102 (Dm-17) e Colorado (Dm-18) são resistentes $(1+$ $2+0+0+16+32=51)$. E por fim, a cultivar Argeles do grupo 4 mostrou-se resistente $(0=00)$.

\section{RESULTADOS E DISCUSSÃO}

Foram identificados três comportamentos de $B$. lactucae na região produtora do estado de São Paulo pelo código "Sextet" 63/31/19/00, 63/63/19/00 e $63 / 63 / 03 / 00$, caracterizando três novas raças de B. lactucae SPB1:02, SPB1:03 e SPB1:04, respectivamente (Tabela 1).

A diferença de comportamento de B. lactucae, consiste na resistência conferida pelo gene Dm-14 (UCDM14) da raça SPBl: 04 com resistência dominante. 
Tabela 1. Reação de plântulas à inoculação com isolados de Bremia lactucae coletados na região produtora de alface do Estado de São Paulo em 2006 (seedling reaction to inoculation by isolates of Bremia lactucae collected in lettuce-producing region of São Paulo in 2006). Jaboticabal, UNESP, 2009.

\begin{tabular}{|c|c|c|c|c|c|c|c|c|c|c|c|c|c|c|}
\hline \multicolumn{2}{|c|}{ Cultivares diferenciadoras } & $\mathbf{A}$ & B & $\mathbf{C}$ & $\mathbf{D}$ & $\mathbf{E}$ & $\mathbf{F}$ & $\mathbf{G}$ & $\mathbf{H}$ & $\mathbf{J}$ & $\mathbf{K}$ & $\mathbf{L}$ & $\mathbf{M}$ & \\
\hline \multicolumn{2}{|c|}{ Genes Dm } & 7 & 10 & 11 & 12 & 13 & 14 & 15 & 16 & 17 & 18 & 36 & 37 & Código \\
\hline \multicolumn{2}{|l|}{ Sextet N } & 7 & 8 & 9 & 10 & 11 & 12 & 13 & 14 & 15 & 16 & 17 & 18 & "Sextet" \\
\hline \multicolumn{2}{|l|}{ Valor } & 1 & 2 & 4 & 8 & 16 & 32 & 1 & 2 & 4 & 8 & 16 & 32 & \\
\hline Isolados & Locais & \multicolumn{6}{|c|}{ Grupo 2} & \multicolumn{6}{|c|}{ Grupo 3} & \\
\hline IB-1 & Ibiúna & + & + & + & + & + & + & + & + & - & - & + & - & $63 / 63 / 19 / 00$ \\
\hline IB-2 & Ibiúna & + & + & + & + & + & + & + & + & - & - & + & - & $63 / 63 / 19 / 00$ \\
\hline IB-3 & Ibiúna & + & + & + & + & + & - & + & + & - & - & + & - & $63 / 31 / 19 / 00$ \\
\hline MC-1 & Mogi dasCruzes & + & + & + & + & + & - & + & + & - & - & + & - & $63 / 31 / 19 / 00$ \\
\hline MC-2 & Mogi dasCruzes & + & + & + & + & + & - & + & + & - & - & + & - & $63 / 31 / 19 / 00$ \\
\hline MC-3 & Mogi dasCruzes & + & + & + & + & + & - & + & + & - & - & + & - & $63 / 31 / 19 / 00$ \\
\hline ARAÇ-1 & Araçatuba & + & + & + & + & + & - & + & + & - & - & + & - & $63 / 31 / 19 / 00$ \\
\hline ARAÇ-2 & Araçatuba & + & + & + & + & + & - & + & + & - & - & + & - & $63 / 31 / 19 / 00$ \\
\hline RP-1 & Ribeirão Preto & + & + & + & + & + & + & + & + & - & - & + & - & $63 / 63 / 19 / 00$ \\
\hline RP-2 & Ribeirão Preto & + & + & + & + & + & + & + & + & - & - & + & - & $63 / 63 / 19 / 00$ \\
\hline $\mathrm{RC}-1$ & Rio Claro & + & + & + & + & + & - & + & + & - & - & + & - & $63 / 31 / 19 / 00$ \\
\hline $\mathrm{RC}-2$ & Rio Claro & + & + & + & + & + & - & + & + & - & - & + & - & $63 / 31 / 19 / 00$ \\
\hline BAU-1 & Bauru & + & + & + & + & + & + & + & + & - & - & - & - & $63 / 63 / 03 / 00$ \\
\hline BAU-2 & Bauru & + & + & + & + & + & + & + & + & - & - & - & - & $63 / 63 / 03 / 00$ \\
\hline SC-1 & São Carlos & + & + & + & + & + & - & + & + & - & - & + & - & $63 / 31 / 19 / 00$ \\
\hline SC-2 & São Carlos & + & + & + & + & + & - & + & + & - & - & + & - & $63 / 31 / 19 / 00$ \\
\hline CAMP-1 & Campinas & + & + & + & + & + & - & + & + & - & - & + & - & $63 / 31 / 19 / 00$ \\
\hline CAMP-2 & Campinas & + & + & + & + & + & - & + & + & - & - & + & - & $63 / 31 / 19 / 00$ \\
\hline ARA-1 & Araraquara & + & + & + & + & + & - & + & + & - & - & + & - & $63 / 31 / 19 / 00$ \\
\hline ARA-2 & Araraquara & + & + & + & + & + & - & + & + & - & - & + & - & $63 / 31 / 19 / 00$ \\
\hline SPB1:02 & & + & + & + & + & + & - & + & + & - & - & + & - & $63 / 31 / 19 / 00$ \\
\hline SPB1:03 & & + & + & + & + & + & + & + & + & - & - & + & - & $63 / 63 / 19 / 00$ \\
\hline SPBl:04 & & + & + & + & + & + & + & + & + & - & - & - & - & $63 / 63 / 03 / 00$ \\
\hline
\end{tabular}

$\mathrm{A}=\mathrm{LSE}$ 57/15; B= UC DM 10; C= Capitan; D= HildeII; E= Pennlake; F= UC DM 14; G= PIVT 1309; H= INRA DM 16; J= LS 102; K= Colorado; L= Ninja; $\mathrm{M}=$ Discovery;

(-): reação incompatível (sem doença); (+): reação compatível (com doença) [(-) incompatible reaction (without disease); $(+)$ compatible reaction (disease)].

A reação de plântulas à inoculação de Bremia lactucae L. nos anos de 2006 e 2007, foi compatível (+) e assim tiveram seus valores somados para todas as cultivares diferenciadoras representantes dos grupos DM0 ('Cobham Green' e Odra) e grupo 1(Lednicky, UC DM-2, Dandie, R4T57DM, Valmaine e Sabine). Já para o grupo 4 constituido somente pelo gene DM-38 (Argeles), obteve reação incompatível (-) para todos os isolados avaliados em ambos os anos de monitoramento, representando assim o valor zero separado por barra.

Foram identificadas no estado de São Paulo as raças SPB1:02, SPB1:03 e SPBl:04 em 2006, mas somente as raças SPB1:02 e SPBl:03 tiveram suas ocorrências também verificadas em 2007 (Tabela 2). Portanto, somando-se ao resultado de Braz et al. (2007), já foram identificadas quatro raças de $B$. lactucae no estado de São Paulo.

A diferença de comportamento das raças de B. lactucae SPB1:02, SPB1:03 SPB1:04 da raça anteriormente identificada como SPB1:01 (Braz et al., 2007), se deve à suscetibilidade conferida pelo gene Dm-37 na formação do código "Sextet". O mesmo comportamento do oomiceto SPB1:01 (63/63/51/00) também foi observado em 2004 no Sul de Minas Gerais (Pissardi et al., 2005), evidenciando ser uma raça de $B$. lactucae que predominava na maioria das regiões produtoras de alface da região Sudeste do Brasil.

O surgimento de novas raças provavelmente deve-se às mutações que, embora raras, são os principais meca- nismos criadores de novas combinações de genes; entretanto, outros mecanismos amplificam a variabilidade criada pela mutação por meio da formação de novas combinações, os chamados mecanismos de recombinação gênica (Borém \& Miranda, 2007).

Os microorganismos que se reproduzem sexuadamente estão entre os que apresentam maior variabilidade fitopatogênica, pois esse modo de reprodução gera uma recombinação meiótica que aumenta a variabilidade genética, 
Tabela 2. Reação de plântulas à inoculação em isolados de Bremia lactucae coletados na região produtora de alface do Estado de São Paulo em 2007 (seedling reaction to inoculation by isolates of Bremia lactucae collected in lettuce-producing region of São Paulo in 2007). Jaboticabal, UNESP, 2009.

\begin{tabular}{|c|c|c|c|c|c|c|c|c|c|c|c|c|c|c|}
\hline \multicolumn{2}{|c|}{ Cultivares diferenciadoras } & $\mathbf{A}$ & $\mathbf{B}$ & $\mathbf{C}$ & $\mathbf{D}$ & $\mathbf{E}$ & $\mathbf{F}$ & $\mathbf{G}$ & $\mathbf{H}$ & $\mathbf{J}$ & $\mathbf{K}$ & $\mathbf{L}$ & $\mathbf{M}$ & \\
\hline \multicolumn{2}{|c|}{ Genes Dm } & 7 & 10 & 11 & 12 & 13 & 14 & 15 & 16 & 17 & 18 & 36 & 37 & Código "Sex- \\
\hline \multicolumn{2}{|c|}{ Sextet $\mathbf{N}^{\circ}$} & 7 & 8 & 9 & 10 & 11 & 12 & 13 & 14 & 15 & 16 & 17 & 18 & tet" \\
\hline \multicolumn{2}{|l|}{ Valor } & 1 & 2 & 4 & 8 & 16 & 32 & 1 & 2 & 4 & 8 & 16 & 32 & \\
\hline \multicolumn{2}{|l|}{ Isolados } & \multicolumn{6}{|c|}{ Grupo 2} & \multicolumn{6}{|c|}{ Grupo 3} & \\
\hline BOT-1 & Botucatu & + & + & + & + & + & + & + & + & - & - & + & - & $63 / 63 / 19 / 00$ \\
\hline BAU-1 & Bauru & + & + & + & + & + & + & + & + & - & - & + & - & $63 / 63 / 19 / 00$ \\
\hline PIED-1 & Piedade & + & + & + & + & + & + & + & + & - & - & + & - & $63 / 63 / 19 / 00$ \\
\hline PIED-2 & Piedade & + & + & + & + & + & + & + & + & - & - & + & - & $63 / 63 / 19 / 00$ \\
\hline ARA-1 & Araraquara & + & + & + & + & + & + & + & + & - & - & + & - & $63 / 63 / 19 / 00$ \\
\hline ARA-2 & Araraquara & + & + & + & + & + & + & + & + & - & - & + & - & $63 / 63 / 19 / 00$ \\
\hline RIB-1 & Ribeirao Preto & + & + & + & + & + & + & + & + & - & - & + & - & $63 / 63 / 19 / 00$ \\
\hline RIB-2 & Ribeirao Preto & + & + & + & + & + & + & + & + & - & - & + & - & $63 / 63 / 19 / 00$ \\
\hline RIB-3 & Ribeirao Preto & + & + & + & + & + & + & + & + & - & - & + & - & $63 / 63 / 19 / 00$ \\
\hline JAB-1 & Jaboticabal & + & + & + & + & + & - & + & + & - & - & + & - & $63 / 31 / 19 / 00$ \\
\hline JAB-2 & Jaboticabal & + & + & + & + & + & - & + & + & - & - & + & - & $63 / 31 / 19 / 00$ \\
\hline BM-1 & Biritiba Mirim & + & + & + & + & + & - & + & + & - & - & + & - & $63 / 31 / 19 / 00$ \\
\hline BM-2 & Biritiba Mirim & + & + & + & + & + & - & + & + & - & - & + & - & $63 / 31 / 19 / 00$ \\
\hline IB-1 & Ibiúna & + & + & + & + & + & + & + & + & - & - & + & - & $63 / 63 / 19 / 00$ \\
\hline IB-2 & Ibiúna & + & + & + & + & + & + & + & + & - & - & + & - & $63 / 63 / 19 / 00$ \\
\hline IB-3 & Ibiúna & + & + & + & + & + & + & + & + & - & - & + & - & $63 / 63 / 19 / 00$ \\
\hline SPBl:02 & & + & + & + & + & + & - & + & + & - & - & + & - & $63 / 31 / 19 / 00$ \\
\hline SPBl:03 & & + & + & + & + & + & + & + & + & - & - & + & - & $63 / 63 / 19 / 00$ \\
\hline
\end{tabular}

$\mathrm{A}=\mathrm{LSE}$ 57/15; B= UC DM 10; C= Capitan; D= HildeII; E= Pennlake; F= UC DM 14; G= PIVT 1309; H= INRA DM 16; J= LS 102; K= Colorado; L= Ninja; M= Discovery;

(-): reação incompatível (sem doença); $(+)$ : reação compatível (com doença) [(-) incompatible reaction (without disease); $(+)$ compatible reaction (disease)].

favorecendo o aparecimento de novas raças que contêm combinações inéditas de genes de virulência. Entretanto, como o modo de reprodução mais comum em B. lactucae é assexuada, existe uma baixa frequência de raças fisiológicas identificadas, ainda que a doença seja considerada de recente ocorrência no Brasil (Bergamin Filho et al., 1995).

A identificação de raça de $B$. lactucae em 2006 na região produtora de alface do estado de São Paulo, a SPBl:02 (63/31/19/00) apresenta um comportamento muito semelhante à raça identificada no Sul da Holanda $(63 / 31 / 51 / 00)$. Os genes que conferiram resistência a essa última raça foram o Dm-14,17 e 18 (Van Der Arend et al., 2006).

Os genes Dm-14, Dm-17, Dm-18, Dm-37 e Dm-38 conferem resistência a essas novas raças identificadas. No entanto o gene Dm-17 encontrado no fenótipo 'LS-102' (Lactuca serriola), que é de uma espécie selvagem do gênero Lactuca (Lebeda \& Petrzelová, 2004) necessita para a introgressão desse gene em cultivar com bom padrão comercial, de um período maior de pesquisa para incorporação da resistência. Por isso, recomenda-se a utilização do gene Dm-18 da cultivar diferenciadora 'Colorado', que por ser portadora do gene Dm promissor à transferência da resistência, e que, por ser encontrado em cultivares comerciais na Europa, é um dos mais recomendados para a utilização em programas visando à resistência ao míldio da alface em menor tempo.

Van Der Arend et al. (2006) identificaram atualmente na Europa 25 raças de $B$. lactucae. Somente no período de 2000 a 2004 quatro novas raças foram identificadas e denominadas de Bl:22;
$\mathrm{Bl}: 23$; Bl:24 e Bl:25 com os comportamentos de B. lactucae: 59/63/09/00; 63/31/02/01; 59/31/10/01 e 59/31/42/00, respectivamente. O gene Dm-36 do genótipo 'Ninja' foi o único que conferiu resistência presente em todas as quatro novas raças identificadas.

$\mathrm{Na}$ Califórnia-EUA, Schettini et al. (1991) também se referem ao surgimento de novas raças de $B$. lactucae em alface com genes de virulência de potencialidades para quebrar a resistência dos genótipos comerciais locais.

O monitoramento de raças de B. lactucae no estado de São Paulo permitiu identificar três novas raças: SPBl:02, SPBl:03 e SPBl:04 com os respectivos comportamentos 63/31/19/00; 63/63/19/00 e 63/63/03/00.

Os genes Dm-14, Dm-17, Dm-18, Dm-37 e Dm-38 conferem resistência a essas novas raças identificadas. Portan- 
to, esses genes deverão ser utilizados em programas de melhoramento genéticos visando resistência a esse microorganismo.

\section{REFERÊNCIAS}

BERGAMIN FILHO A; KIMATI H; AMORIM L. 1995. Manual de Fitopatologia: Princípios e Conceitos. 3.ed. São Paulo: Agronômica Ceres. v.2, 919p.

BORÉM M; MIRANDA GV. 2005. Melhoramento de plantas. 4 ed. Viçosa: UFV. 525p.

BRAZ LT; DALPIAN T; PISSARDI MA. 2007. Identification of races of Bremia lactucae in São Paulo, Brazil. Acta Horticulturae p.317321. 760 .

BRUGGEN AHC; SCHERM H. 1997. Downy mildew. In: DAVIS MR. Compendium of Lettuce Diseases, Saint Paul: APS PRESS, p. 17-19.

CATI, 2008. Mapas da Agricultura Paulista: principais atividades agrícolas, in: < http:// www.cati.sp.gov.br/servicos/index.htm> Acesso em: 25/03/2008.

CRUTE IR; JOHNSON AG. 1976. Breeding for resistance to lettuce downy mildew, Bremia lactucae. Ann. Appl. Biol. 84: 287-290.

ETTEKOVEN K; VAN DER AREND AJM. 1991. Identification and denomination of new races of Bremia lactucae. Proceeedings of Eucarpia Meeting on Leafy Vegetables Genetics and Breeding. Olomuc, Czech Republic. p. 105107.

IEA. 2009. Estatísticas da produção vegetal, por produto, total do estado de São Paulo, 2009. In: < http://www.iea.sp.gov.br/fanu-pre.htm> Acesso em: 22/02/2009.

ILOTT TW; DURGAN ME; MICHELMORE RW. 1987. Genetics of virulence in California populations of Bremia lactucae (Lettuce Downy Mildew). Phytopathology 77: 13811386.

LEBEDA A; PETRZELOVÁ, L. 2004. Variation and distribution of virulence phenotypes of Bremia lactucae in natural populations of Lactuca serriola. Plant Pathology 53: 316-324.

PAVAN MA; KUROZAWA C. 1997. Doenças da alface. In: KIMATI H. Manual de Fitopatologia: Doenças das plantas cultivadas. v. 2, São Paulo: Ceres. p. 18-25.
PISSARDI MA; DALPIAN T; BRAZ LT; CAMARGO M. Identificação do comportamento de Bremia lactucae polo produtor de alface americana do Sul de Minas Gerais. In: 45 Congresso Brasileiro de Olericultura, 2005, Fortaleza-CE. Horticultura Brasileira. Brasília-DF: ABH, v. 23, 2005.

SCHETTINI TM; LEGG EJ; MICHELMORE RW. 1991. Insensitivity to metalaxyl in California populations of Bremia lactucae and resistance of California lettuce cultivars to downy mildew. Phytopathology. 81: 64-70.

VAN DER AREND AJM; GAUTIER J; GRIMAULT V; KRAAN P; VAN DER LAAN R; MAZE J; MICHEL H; SCHUT JW; SMILDE D; WITTE I. 2006. Identification and denomination of new races of Bremia lactucae in Europe by IBEB until 2006. The international Bremia evaluation board-IBEB. Europa. 2006.

VAN ETTEKOVEN K; VAN DER AREND A. 1999. Identification and denomination of "new" races of Bremia lactucae. Proceedings of Eucarpia Meeting on Leafy Vegetables Genetics and Breeding. Olomuc: Czech Republic, p. 105-107. 